\title{
La naturaleza como sujeto de derechos: análisis bioético de las Constituciones de Ecuador y Bolivia*
}

\author{
Nature as subject of rights: a bioethical analysis of \\ the Constitutions of Ecuador and Bolivia
}

A natureza como sujeito de direitos: uma análise bioética das Constituições do Equador e da Bolívia

Fecha de recepción: 31 de julio de 2017

Fecha de evaluación: 28 de septiembre de 2017

Fecha de aceptación: 31 de octubre de 2017

Disponible en línea: 21 de noviembre de 2017

Irene Zasimowicz Pinto Calaça**

Patrícia Jorge Carneiro de Freitas**

Sérgio Augusto da Silva**

Fabiano Maluf ***

\author{
Cómo citar: \\ Pinto Calaça, I. Z., Cerneiro de Freitas, P. J. Da Silva, \\ S. A. y Maluf, F. (2018). La naturaleza como sujeto \\ de derechos: análisis bioético de las Constituciones \\ de Ecuador y Bolivia. Revista Latinoamericana de \\ Bioética, 18(1), 155-171. \\ Doi: https://doi.org/10.18359/rlbi.3030
}

* $\quad$ El artículo se desprende del trabajo final desarrollado en el $18^{\circ}$ Curso de Especialización en Bioética de la Cátedra Unesco de Bioética, de la Universidad de Brasilia (UnB), concluido en diciembre de 2016. Los autores declaran no haber conflicto de intereses.

** Alumnos del Curso de Especialización en Bioética de la Cátedra Unesco de Bioética, de la Universidad de Brasilia (UnB), Brasil.

*** Doctor en Ciencias de la Salud, Universidad de Brasilia (UnB), Brasil. Correo electrónico: maluffabiano@bol. com.br. ORCID: https://orcid.org/0000-0002-3395-069X 
Las filosofías de la Pachamama y del buen vivir son puntos de referencia de los pueblos indígenas y están presentes en las constituciones de Ecuador y Bolivia, con el fin de armonizar las diferencias culturales y añadir las tradiciones a la política local. Las filosofías toman por base un mito andino: el que cree que la naturaleza es un organismo vivo y sujeto de derechos, y se abren espacio a la visión biocéntrica del mundo, compartida por la bioética global. La naturaleza ya no logra recomponerse por las innovaciones biotecnológicas impuestas por el hombre, lo que obliga a la humanidad a encontrar nuevos paradigmas, el Nuevo Constitucionalismo Latinoamericano, representado por las constituciones, es uno de ellos. En este artículo se describen y analizan críticamente estas dos constituciones, relacionándolas con la visión de mundo de la Pachamama y de la filosofía del buen vivir en el contexto de la bioética global. En este sentido, la Declaración Universal sobre Bioética y Derechos Humanos, al asociar bioética como campo normativo particular en la atención y cuidado de la vida y de la salud, con derechos humanos como campo normativo universal básico de obligaciones morales y jurídicas para todas las formas de vivir humano, presenta los valores fundamentales de una ética universal sustentada por la dignidad humana, la igualdad de derechos, la libertad, la justicia, la fraternidad y la paz, como es defendido en el artículo 17, de la protección del medio ambiente, de la biósfera y de la biodiversidad.

Palabras clave: medio ambiente, naturaleza, bioética, sostenibilidad.

\section{Abstract}

Resumo

The philosophies of Pachamama and good living are points of reference for indigenous peoples and are present in the constitutions of Ecuador and Bolivia, to harmonize cultural differences and add traditions to local politics. The philosophies take as a base an Andean myth: the one who believes that nature is a living organism and subject of rights and make room to the biocentric vision of the world, shared by global bioethics. Nature no longer manages to recompose itself for the biotechnological innovations imposed by man, which forces humanity to find new paradigms, the New Latin American Constitutionalism, represented by the constitutions, is one of them. This article describes and critically analyzes these two constitutions, relating them to the worldview of the Pachamama and the philosophy of good living in the context of global bioethics. In this sense, the Universal Declaration on Bioethics and Human Rights, by associating bioethics as a particular normative field in the attention and care of life and health, with human rights as a basic universal normative field of moral and legal obligations for all forms of living humanly, presents the fundamental values of a global ethic sustained by human dignity, equality of rights, freedom, justice, fraternity and peace, as defended in article 17, of the protection of the environment, of the biosphere and biodiversity.

Keywords: Environment, nature, bioethics, sustainability.

As filosofias da Pachamama e do bom viver são pontos de referência dos povos indígenas e estão presentes nas constituições do Equador e da Bolívia, a fim de harmonizar as diferenças culturais e agregar as tradições às políticas locais. As filosofias são baseadas em um mito andino: aquele que acredita que a natureza é um organismo vivo e sujeito de direitos e se abre espaço para a visão biocêntrica do mundo, compartilhada pela bioética global. A natureza já não consegue recompor-se pelas inovações biotecnológicas impostas pelo homem, o que obriga à humanidade a encontrar novos paradigmas, o Novo Constitucionalismo Latino-americano, representado pelas constituições, é um deles. Neste artigo se descrevem e analisam criticamente essas duas constituições, relacionando-as com a visão de mundo da Pachamama e da filosofia do bom viver no contexto da bioética global. Nesse sentido, a Declaração Universal sobre Bioética e Direitos Humanos, ao associar bioética como campo normativo particular na atenção e cuidado da vida e da saúde, com direitos humanos como campo normativo universal básico de obrigações morais e legais para todas as formas de viver humano, apresenta os valores fundamentais de uma ética universal sustentada pela dignidade humana, a igualdade de direitos, a liberdade, a justiça, a fraternidade e a paz, como é defendido no artigo 17, da proteção do meio ambiente, da biosfera e da biodiversidade.

Palavras-chave: meio ambiente, natureza, bioética, sustentabilidade. 


\section{Introducción}

Recientemente, pasaron a ser difundidos en el escenario mundial referenciales de pueblos indígenas andinos, como la Pachamama y la filosofía del buen vivir, que se expandieron en América Latina a través de movimientos sociales de poblaciones excluidas (indígenas, quilombolas y otras comunidades tradicionales). Estos pueblos creen que por medio de la sostenibilidad ambiental se alcanza la sostenibilidad social y la mitigación de la acentuada desigualdad socioeconómica entre países centrales y periféricos (Winckler y Pereira, 2013; Nogueira y Dantas, 2012).

La Pachamama y la filosofía del buen vivir fueron reconocidas en los principales instrumentos jurídicos de Ecuador y Bolivia al inicio de los años 2000, y con esto se inauguró un movimiento denominado Nuevo Constitucionalismo Latinoamericano, en el que las perspectivas eurocéntrica y antropocéntrica dominantes en la cultura mundial (Rivas-Muñoz, Garrafa, Feitosa y Nascimento, 2015; Garrafa, Martorell y Nascimento, 2016) fueron substituidas por la visión de mundo biocéntrica de los pueblos amerindios.

Para ese momento, la bioética global ya venía trabajando la necesidad de asimilar el paradigma biocéntrico. Cuestiones ambientales relacionadas con la sobrevivencia en la Tierra, frente a los cambios ocasionados por la evolución tecnológica humana (Junges, 2014; Pombo, Junges y Nascimento, 2015), fueron colocadas por Van Rensselaer Potter al inicio de los años setenta, retomadas en los años noventa y aplicadas en 2005 a la Declaración Universal sobre Bioética y Derechos Humanos (DUBDH), proclamada por la Unesco.

Haciendo una investigación discursiva, el presente artículo describe y analiza crítica- mente las constituciones de Bolivia y Ecuador, relacionándolas con la visión de mundo de la Pachamama y del buen vivir, desde la perspectiva de la bioética global y de la DUBDH. Así pues, primero temas y conceptos son contextualizados; luego, discutimos cómo las constituciones de Bolivia y Ecuador tratan la naturaleza, apuntamos contribuciones de la bioética global y de la DUBDH, $\mathrm{y}$ traemos nuestras consideraciones finales.

\section{Contextualización del tema}

El término naturaleza viene de la palabra latina natura; la raíz "nasci" significa "acción de hacer nacer". En griego, el término usado para naturaleza era más amplio: la palabra physis, que va más allá del ser humano e incorpora la contraposición entre natural y artificial. El significado de naturaleza puede variar a lo largo del tiempo y no es necesariamente el mismo para diferentes grupos sociales en la misma época (Dulley, 2004).

A partir de la naturaleza y del acúmulo de conocimiento sobre ella, fue construido el medio ambiente del hombre. La suma de los medios ambientes del hombre y de las otras especies resulta en el ambiente. El ambiente es la naturaleza conocida por el sistema social humano (compuesto por el medio ambiente humano y el medio ambiente de las demás especies), de acuerdo con Dulley (2004).

Transformar la naturaleza en fuente inagotable de recursos naturales exclusivos de seres humanos acarrea consecuencias nefastas para la biósfera. Este tipo de explotación también levanta dudas sobre la capacidad que tiene la modernidad para ser impuesta como patrón a todos los habitantes del planeta. El modelo económico vigente en el mundo contemporáneo es insostenible, pues está pautado en el individualismo, en la 
venta de la fuerza de trabajo para el acúmulo de capital y en la expansión de la gran propiedad privada (Nogueira y Dantas, 2012).

Por otro lado, comunidades tradicionales utilizan sistemas sostenibles de manejo de los recursos naturales, o sea, sistemas en los cuales la explotación de la naturaleza se encuentra adecuada a la capacidad de recuperación de las especies de animales y plantas, de acuerdo con los ciclos naturales. Estas comunidades también aplican valores sociales y conocimientos heredados de los más viejos a través de mitos y simbologías, para lo cual se usan de forma sostenible los ecosistemas y se evita así la explotación económica de los recursos naturales, al contrario de lo que vigora en el sistema eurocéntrico y colonizador bastante difundido (Garrafa et al., 2016; Diegues, 1993).

Según Junges (2006), la modernidad posee tres valores básicos. El primero es el individualismo impulsado por la autonomía, mientras que en las sociedades tradicionales la identidad era dada por la comunidad, a través de los lazos comunitarios. El debilitamiento de estos lazos, producido por la modernidad, hizo surgir el individuo autónomo, caracterizado por aquello que lo diferencia de los demás y no por aquello que lo identifica con su grupo. Cada individuo es invitado a ser original y auténtico en su expresión. No obstante, el "yo" que de ahí surge, aunque no sea egoísta, es fragmentado, sin identidad, narcisista. El sujeto autónomo, sin identidad, queda a merced de las emociones del momento y se vuelve manipulable.

El segundo de la modernidad es el progreso técnico-científico. Originalmente direccionado a eventuales beneficios que traía a la humanidad, este progreso pasó a fragmentar la realidad para alcanzar sus objetivos, lo que retiró la visión sistémica y holística del mundo y produjo así desastres ambientales y sociales. Para quebrar el paradigma instaurado, surge la ecología, que se vuelve alternativa a esta visión reductora del mundo, que equipara la naturaleza a los recursos naturales para humanos. La ecología comprende el mundo como una serie de procesos autoorganizados e interconectados, caracterizados por la colaboración, flexibilidad, el reciclaje y la diversidad (Junges, 2006; Capra, 1996).

El tercer valor de la modernidad es la sociedad democrática del mercado y del Estado. La sociedad moderna, por medio del mercado invisible, cosifica las relaciones, y reduce todo a la mercaduría y al Estado tutelar, que se expresa en el aparato burocrático de poder. La democracia queda reducida a la participación en los momentos de las elecciones. Como la sociedad se encuentra fragmentada, la libertad del ciudadano de consumir productos, participar de actos de protesta y tener iniciativas libres de expresar sus opiniones no es suficiente para la formulación de objetivos comunes.

Es posible que los ciudadanos se sientan ligados a determinados proyectos comunes, pero estos son siempre agrupamientos parciales corporativos, reunidos por intereses concretos y no por la sociedad en su conjunto. En esta situación de atomización y fragmentación, la democracia social se vuelve una ficción, porque se reduce a las batallas judiciales para defender derechos e intereses de grupos determinados, pero no los intereses de la sociedad como un “todo” (Junges, 2006).

En un contexto de búsquedas por alternativas que mejoren la coexistencia humana con la biodiversidad, surge el Nuevo Constitucionalismo Latinoamericano, un intento de perspectiva holística, entre medio ambiente 
y seres humanos, incorporado por las Constituciones de Ecuador (2008) y Bolivia (2009). Estas constituciones registran la filosofía del buen vivir (sumak kawsay en Ecuador y suma qamaña en Bolivia), en contrapunto al modelo de desarrollo económico capitalista moderno:

[...] el "buen vivir" apunta a una ética de lo suficiente para toda la comunidad, y no solamente para el individuo. El "buen vivir" supone una visión holística e integradora del ser humano, inmerso en la gran comunidad terrenal, que incluye además de al ser humano, al aire, el agua, los suelos, las montañas, los árboles y los animales; es estar en profunda comunión con la Pachamama (Tierra), con las energías del Universo, y con Dios. (Boff, 2012, p. 66)

La concepción de los pueblos indígenas sobre la relación con la naturaleza (Pachamama), la filosofía del buen bivir, se vuelve un verdadero rescate de la cultura amerindia después de siglos de la imposición cultural colonialista eurocéntrica, y es introducida en la Constitución de Ecuador de 2008 y de Bolivia de 2009. Pachamama es un mito andino que surge de la cultura local y del culto a la tierra de los aborígenes en la Cordillera de los Andes, durante el proceso de colonización de los españoles. "Pacha" significa el universo, el mundo, y "mama", madre. Así, Pachamama puede ser interpretado como madre tierra en el sentido de tierra grande, directora y sustentadora de la vida, tierra como organismo vivo. Pachamama también se revela como manifestación de saber de la cultura ancestral de convivencia con la naturaleza (Tolentino y Oliveira, 2015).

Para los pueblos que aún mantienen este vínculo explícito y consciente con la tierra, la naturaleza representa a una madre, probablemente la más importante, pues es la madre de todo lo que crece en ella y a su vez hay una conciencia de ésta como parte de un sistema integral, como proveedora se le respeta, no es un objeto sino un sujeto que interactúa con el yo, no es alteridad absoluta ni se le ve como una oposición entre el ser que la habita y sus ideales de vida, sino como parte de ellos mismos. Para muchas cosmovisiones indígenas la madre tierra es el sujeto con el que se establecen diálogos permanentes de cuyo resultado, somos testigos, se construyen complejas construcciones culturales e identidades históricamente ecológicas; muestra de ello son los mitos creacionales o mitos fundacionales de las culturas indígenas que han sido repetidos miles de veces por cientos de generaciones a través del tiempo. Para las culturas indígenas "no hay nada que no tenga corazón o principio de vida, es decir, todo vive", y en una sociedad en la que todo vive las relaciones se hacen entre sujeto-sujeto y no entre sujeto-objeto. (Martínez, 2010, p. 2)

La concepción del buen vivir es semejante a la noción de "bien común de la humanidad", desarrollada por la Organización de las Naciones Unidas (ONU) en sus prácticas internacionales (Nogueira y Dantas, 2012). Pacta también con los artículos 16 y 17 de la DUBDH en la búsqueda por soluciones para cuestiones de protección al medio ambiente, biósfera, biodiversidad y generaciones futuras.

Esta filosofía ocasiona un cambio en la perspectiva moderna, por aceptar la lógica de las diversidades cultural, étnica y social, y por combatir los daños hegemónicos colonialistas. El reconocimiento de la naturaleza como sujeto de derecho colectivo implica la pérdida parcial de la titularidad de los derechos indivi- 
duales. De ahí adviene la dificultad del reconocimiento del buen vivir dentro del sistema capitalista individualista, en el cual el Estado y el derecho monista se encuentran institucionalizados (Dulley, 2004; Souza Filho, 1999). En el próximo tópico presentamos cómo las Constituciones de Ecuador y Bolivia superan esas dificultades y retoman la visión biocéntrica de naturaleza existente en las comunidades locales.

\section{Las Constituciones de Bolivia y Ecuador}

Bolivia y Ecuador son Estados plurinacionales. No obstante, desde su colonización hasta mediados del siglo XX, la diversidad cultural de las poblaciones nativas locales fue reprimida y colocada al margen de los poderes públicos históricamente impuestos. Por lo menos dos paradojas de la sociedad multicultural se destacaban: "i) la oposición entre la diversidad de la población y del gobierno oriundo de un modelo único y (ii) las múltiples matrices culturales, en contraste con la rigidez y uniformización de las instituciones públicas estatales" (Afonso y Magalhães, 2011, p. 9).

La implantación de las nuevas constituciones buscó armonizar las diferencias culturales y agregar al seno político tradiciones y costumbres de las comunidades existentes. La voluntad popular mayoritaria volvió a ser manifestada en las constituciones, lo que originó el Nuevo Constitucionalismo Latinoamericano. Este fenómeno emerge de grupos sociales excluidos por los colonizadores ?naciones indígenas, poblaciones afroamericanas, masas de campesinos agrarios y múltiples movimientos urbanos? y se contrapone a la visión de mundo hegemónica eurocéntrica-estadunidense, caracterizada por el antropocentrismo.
Juntamente con el biocentrismo y el ecocentrismo, el antropocentrismo constituye una doctrina ética ambiental surgida a lo largo de la historia de la humanidad. La visión antropocéntrica coloca al ser humano en el centro del universo, sometiendo todo lo demás a su alrededor. En esta perspectiva, la protección ambiental sirve al hombre, al mismo tiempo en que la naturaleza es comprendida desde un punto de vista exclusivamente instrumental(Amado, 2014).

El biocentrismo sustenta la existencia de valor en los demás seres vivos, independientemente de la presencia del hombre. La vida es considerada un fenómeno único, teniendo la naturaleza valor intrínseco y no apenas instrumental, lo que implica considerar a los seres vivos no integrantes de la raza humana (Amado, 2014). Para el biocentrismo, la biodiversidad es el centro del universo.

De la misma forma, el biocentrismo respeta a los seres sintientes (seres que poseen la capacidad de sensibilidad y consciencia) y a los no sintientes, pues ambos se encuentran en simbiosis (uno no vive sin el otro) (Singer, 2010). El límite de la sentencia es la frontera diferencial de una mayor preocupación por el interés ajeno. La capacidad de sufrir y de sentir placer es vital, además de un prerrequisito para que un ser se convierta en objeto de interés, $y$, por consiguiente, la igualdad de consideración debe existir independiente de la especie (Singer, 2002, 2010).

El ecocentrismo posee una idea más amplia que el biocentrismo, al presentar valores centrados en la naturaleza y defender la igualdad total entre seres bióticos y abióticos; no habría diferenciación entre seres humanos y no humanos, y la naturaleza estaría capacitada a volverse sujeto de derechos (Almeida, 2014). 
Las Constituciones de Ecuador y Bolivia abren espacio a las visiones biocéntrica y ecocéntrica del mundo, y crean un nuevo paradigma, el Nuevo Constitucionalismo Latinoamericano, que innova con la protección al medio ambiente en las constituciones locales, con base en referencias tradicionales, como Pachamama y buen vivir. Al mismo tiempo, estos países adoptan en sus Cartas Magnas el Estado plurinacional, caracterizado por el reconocimiento de las diversidades étnicas y culturales, y que busca promover la dignidad y resolver cuestiones involucrando desigualdades sociales, protección y restauración de la naturaleza (Moura, 2012).

En relación con el medio ambiente, la Constitución de Bolivia emplea la concepción del buen vivir a partir del concepto de Suma Qumaña, pero apenas reconoce la relevancia del derecho a los recursos naturales como patrimonio común y su necesidad de protección y preservación.

En la Carta Magna boliviana, los puntos dedicados al tema del medio ambiente son los artículos 33 y 34, 342 a 347, 348 a 358, y 373. Esta carta apenas menciona el derecho de las personas a un medio ambiente saludable y a calidad de vida, lo que confirma una visión de mundo antropocéntrica, y no incluye el reconocimiento de los derechos de la naturaleza, o sea, la Pachamama como sujeto de derechos, a pesar de hacer alusión a esta en el preámbulo constitucional (Constitución Política del Estado Plurinacional de Bolivia, 2009).

No obstante, por medio de legislación infraconstitucional, Bolivia asegura los derechos de la Madre Tierra (Pachamama) en la Ley 71/2010 (Bolivia, 2010). En el artículo 5 de la referida Ley, es reconocido el carácter jurídico de la Madre Tierra como sujeto colectivo de interés público. En su artículo 2, identifica la interculturalidad como principio para el ejercicio de los derechos de la Madre Tierra, reafirmando la necesidad de diálogo para que todas las culturas del mundo convivan en armonía con la naturaleza y recuperen y mantengan sus valores, saberes y conocimiento (Gaceta Oficial de Bolivia, 2010).

El artículo 6 declara que todas las bolivianas y bolivianos integran la comunidad de seres que componen la Madre Terra y ejercen los derechos establecidos en esta ley. Elemento diferenciador de la Ley 71/2010 es el artículo 10, que crea la Defensoría de la Madre Tierra, que tiene como una de sus misiones velar por el cumplimiento de los derechos previstos para la Pachamama (Gaceta oficial de Bolivia, 2010).

En la Constitución de Bolivia, cabe destacar el artículo 255, que trata de las relaciones internacionales y en su ítem II.8 prohíbe de forma expresa la importación, producción y comercialización de organismos genéticamente modificados y elementos tóxicos que dañen la salud y el medio ambiente (Constitución Política del Estado Plurinacional de Bolivia, 2009).

Los artículos 342 a 347 hablan del equilibrio del medio ambiente por medio de un aprovechamiento sostenible de los recursos naturales. Los artículos 348 a 358 tratan de los recursos naturales, como agua, aire, suelo y subsuelo. El artículo 373 inaugura el capítulo dedicado a los recursos hídricos.

La concepción del buen vivir en Bolivia adopta:

A noção de Suma Qumaña (sic) dos Aymaras da Bolívia significa a complementaridade social, rechaçando a exclusão e a discriminação e buscando a harmonia da 
humanidade com a "Mãe Terra", respeitando as leis da natureza. Tudo isso constitui uma cultura de vida, em oposição a uma vida de morte. Ainda, o Suma Qamaña pode ser visto como "conviver bem", ressaltando assim a necessária convivência dos homens entre si e a natureza.(Moura, 2012, p. 18) ${ }^{1}$

Así, se registra que, por medio de la legislación infra constitucional, Bolivia reconoce los derechos de la Madre Tierra (Pachamama) o naturaleza (Gudynas, 2010).

Por su parte, la Constitución de Ecuador es la principal referencia jurídica del Nuevo Constitucionalismo Latinoamericano. Esta conservó los derechos tradicionales a un medio ambiente saludable y a la calidad de vida, y, de forma inédita, incluyó los derechos de la naturaleza. En este caso, reconoce a la naturaleza como titular de derechos por sus propios valores y, por tanto, como sujeto de derechos(Moura, 2012, p. 18).

Así, ocurre la transformación de la visión antropocéntrica de mundo a la biocéntrica, en la cual la naturaleza y sus recursos naturales no son ya vistos como mercaduría y, por tanto, como bien y objeto de la relación jurídica, sino que se vuelven el centro del mundo, donde el hombre está inserido y del cual hace parte.

1 "La noción de suma qumana de los Aymaras de Bolivia significa la complementaridad social, rechazando la exclusión y la discriminación, y buscando la armonía de la humanidad con la Madre Tierra, respetando las leyes de la naturaliza. Todo esto constituye una cultura de vida, que se opone a una vida de muerte. Todavía, el suma qumana puede ser visto como convivir bien, resaltando así la necesaria convivencia de los hombres entre si y la naturaliza" (Moura, 2012, p.18, traducción de los autores).
La Pachamama y la filosofía del buen vivir son mencionadas en el preámbulo de la Constitución del Ecuador:

CELEBRANDO a la naturaleza, la Pacha Mama, de la que somos parte y que es vital para nuestra existencia" [...] "Decidimos construir una nueva forma de convivencia ciudadana, en diversidad y armonía con la naturaleza, para alcanzar el buen vivir, el sumak kawsay; Una sociedad que respeta, en todas sus dimensiones, la dignidad de las personas y las colectividades. (Constitución del Ecuador, 2008, p. 15)

En la Constitución de Bolivia, el artículo 10 declara de forma expresa que la naturaleza será titular de derechos reconocidos:

Artículo 10. - Las personas, comunidades, pueblos, nacionalidades y colectivos son titulares y gozarán de los derechos garantizados en la Constitución y en los instrumentos internacionales. La naturaleza será sujeto de aquellos derechos que le reconozca la Constitución (Constitución Política del Estado Plurinacional de Bolivia, 2009, p. 21).

El capítulo segundo en la Constitución del Ecuador trae los derechos del buen vivir; en este, los artículos 12 y 13 reconocen respectivamente el derecho humano al agua y el derecho a alimentos saludables y nutritivos. Los artículos 14 y 15 tratan del ambiente saludable. En el artículo 15 son prohibidas, por ejemplo, la producción, comercialización e importación de productos genéticamente modificados por ser perjudiciales para la salud humana y atentar contra la soberanía alimentar y los ecosistemas (Constitución del Ecuador Ecuador, 2008). 
El capítulo séptimo trata específicamente de los derechos de la naturaleza (Pachamama): el artículo 71 reconoce el derecho que la naturaleza tiene de reproducirse, realizar la vida y regenerar sus ciclos vitales. Cualquier persona podrá exigir el cumplimiento de estos derechos junto a autoridades públicas (Constitución del Ecuador, 2008). De acuerdo con Gussoli (2014), la Constitución del Ecuador es el único instrumento jurídico constitucional que reconoce a la naturaleza como sujeto de derechos y que cita de forma explícita los derechos del buen vivir o Sakaw Kawsay al lado de los derechos humanos.

El artículo 72 menciona el derecho de restauración de la naturaleza y el artículo 73 trata de medidas de precaución y restricción para actividades que puedan conducir a la extinción de especies, a la destrucción de ecosistemas y a la alteración permanente de los ciclos naturales. También prohíbe la introducción de organismos y material orgánico e inorgánico que pueda alterar de manera definitiva el patrimonio genético nacional. El artículo 74 revela el derecho de las personas a beneficiarse con el ambiente y las riquezas naturales que les permita el buen vivir (Constitución del Ecuador, 2008).

El texto ecuatoriano defiende valores intrínsecos de la naturaleza, como los valores de las especies vivas y de los ecosistemas, independientemente de la apreciación humana. El sumak kawsay comprende la relación de armonía que debe existir entre el ser humano con la Madre Tierra, lo que implica relacionarse con la naturaleza de tal manera que asegure tanto el bienestar de las personas, como la sobrevivencia de los ecosistemas (Viana, 2013).

Así, la Constitución del Ecuador extiende la personalidad jurídica a entes no huma- nos, como es el caso de la naturaleza, reconociéndola como titular de derechos, o sea, sujeto de derechos. "Portanto, observa-se que o Equador é pioneiro na constitucionalização dessa mudança de cosmovisão, uma vez que consagra os direitos da Mãe terra em sua norma de mais alto valor e hierarquia" (Viana, 2013, p. 23).

La perspectiva biocéntrica de mundo encontrada en el Nuevo Constitucionalismo Latinoamericano es compartida por la bioética global, que recuerda a la humanidad que somos parte de una naturaleza que está siendo diezmada por cambios globales que nosotros mismos causamos. Más adelante examinamos algunas de las contribuciones traídas por la bioética al medio por el cual la DUBDH de la Unesco examina la relación del hombre con la naturaleza.

\section{La contribución de la Bioética Global y de la Declaración Universal sobre Bioética y Derechos Humanos}

La bioética global, surgida en el inicio de los años setenta, levanta cuestiones relacionadas con la sobrevivencia en la Tierra, en términos globales, frente a los cambios ocasionados por la evolución tecnológica humana (Pombo et al., 2015; Junges, 2014).

La tecnología dio al hombre poder inmensurable: "nada se equivale no passado ao que o homem é capaz de fazer no presente e se verá impulsionado a seguir fazendo, no exercício irresistível desse seu poder" (Jonas, 2006, p. 21). El poder acarrea responsabilidad. "O exercício do poder sem a observação do dever é, então, 'irresponsável', ou seja, representa 
uma queda de confiança presente na responsabilidade" (Jonas, 2006, p. 168). ${ }^{2}$

Así, es responsabilidad del hombre proteger a la naturaleza para las generaciones futuras y para la propia vida, pues dada la importancia de la naturaleza, esta debe ser reconocida como un "objeto", con bien y valor intrínsecos, que clama la responsabilidad del sujeto (ser humano), consciente de su poder, para que este actúe en su protección.

[...] não basta o respeito, pois esse reconhecimento emocional da dignidade do objeto que percebemos, por mais intenso que seja, pode permanecer inoperante. Só o sentimento de responsabilidade, que prende este sujeito àquele objeto, pode nos fazer agir em seu favor.(Jonas, 2006, p. 163) 3

Uno de los diferenciales de la bioética global es considerar a la especie humana como integrante de la biósfera y no como un ente superior a los demás seres vivos (Potter y Potter, 1995). Sin embargo, otra corriente bioética surgió en esa época: el principialismo estadounidense, de características antropocéntricas, que busca soluciones inmediatas y concretas para cuestiones bioéticas médicas, a partir de una lista de principios para ser revisada delante de los conflictos morales de salud y tecnocientíficos (Maluf, 2007). En la práctica, esta corriente no contemplaba cuestiones sociales y ambientales mun-

2 "El ejercicio del poder sin la observación del deber es irresponsable, o sea, representa una caída de la confianza presente en la responsabilidad" (Jonas, 2006, p. 168, traducción de los autores).

3 "No basta el respeto, pues este reconocimiento emocional de la dignidad del objeto que percibimos, por más intenso que sea, puede permanecer inoperante. Sólo el sentimiento de responsabilidad que une el sujeto a aquel objeto, puede hacernos actuar a su favor" (Jonas, 2006, p. 163, traducción de los autores). diales. "É necessário conceber o mundo como um todo integrado por uma rede complexa de interdependências e não como simples agregado de partes: assumir o mundo como uma aldeia. Nosso compromisso é aprender a cuidar do planeta" (Junges, 2006, p. 32). ${ }^{4}$

En los años noventa, las críticas a la bioética principialista se intensifican, pues reflejos de los conflictos sociales y ambientales pasan a irradiar en el bienestar y salud de las personas (Junges, 2006). En 1998, a partir del Fourth World Congress of Bioethics, en Japón, las discusiones sobre salud, calidad de vida, biodiversidad y recursos naturales, conducidas por la bioética global, reciben un nuevo aliento y son ampliadas.

En el Sexto Congreso Mundial de Bioética, que tuvo lugar en Brasil, en 2002, el fortalecimiento de esta línea fue mantenido por bioeticistas latinoamericanos, que pasan a abogar por una nueva bioética, más politizada y comprometida, con el objetivo de enfrentar problemas emergentes y persistentes en las naciones en desarrollo (Garrafa, 2005).

La bioética global se fortaleció y colaboró para que, en 2005, bajo la égida de la Unesco, fuera elaborada la DUBDH , un compromiso jurídico internacional, a través del cual países de las Naciones Unidas pactaron encontrar soluciones para cuestiones bioéticas involucrando salud y dignidad humanas, entre otras, de forma plural y universalizada, inclusive a través de la protección al medio ambiente, biósfera, biodiversidad y a las generaciones futuras (Unesco, 2005).

$4 \quad$ "Es necessario concebir el mundo como un todo integrado por una red compleja de interdependencias y no como un simple agregado de partes: asumir el mundo como una aldea. Nuestro compromiso es aprender a cuidar el planeta" (Junges, 2006, p. 32, traducción de los autores). 
La naturaleza ya no logra recomponerse de las alteraciones causadas en su seno por el hombre. Conscientes de esta vulnerabilidad y buscando remediarla, corrientes de pensamiento dispares se unifican en este documento internacional que deja atravesar las marcas de los diferentes autores que la componen para llegar a un consenso.

El Principialismo, de características antropocéntricas, reduce la preocupación por la naturaleza a la finalidad de preservar la vida y salud humanas para esta y para generaciones futuras. La Bioética Global, por otro lado, pone al hombre y al poder de la técnica como "integrante de la" y "responsable por la" naturaleza. No obstante, visiones bioéticas distintas amoldan los preámbulos de la Declaración, bien como los tres artículos que versan sobre cuestiones ambientales.

En las proposiciones iniciales, la DUBDH reconoce la necesidad de dar una respuesta global a las transformaciones causadas por la ciencia y la tecnología (C\&T) en la comprensión de la vida en sí, un pensamiento claramente bioético global. Inmediatamente después, clama por la necesidad de "principios universales" para atender a dilemas tecno científicos para la especie humana y el medio ambiente, lo que recuerda su estructura principialista.

La gran mayoría de los artículos que integran las "Disposiciones Generales" de la DUBDH son constituidos por tópicos principialistas - principios de dignidad humana y derechos humanos, beneficio y daño, autonomía y responsabilidad individual, consentimiento, entre otros. En el documento, la naturaleza es recordada con expresiones como "dimensión ambiental", "protección de las generaciones futuras" y "protección del medio ambiente, de la biósfera y de la biodi- versidad" - estas dos últimas claramente expresando ideas de bioeticistas globales y de intervención (Unesco, 2005).

El vínculo indisoluble de la bioética con los derechos humanos para la defensa de la dignidad humana es recordado en el artículo 3. El bienestar de los individuos y sus intereses deben ser priorizados frente a los avances de las tecnociencias, pues ciertos condicionantes económicos y sociales pueden generar, a veces, impactos negativos y cambios en la salud humana y en la calidad de vida de las personas, y causar así exclusión social o simplemente su agravamiento (Bergel, 2015).

El artículo 14, que trata de la "responsabilidad social y salud", unifica los abordajes antropocéntrico y global, al colocar a Gobiernos y sociedad como responsables por la "mejoría de condiciones de vida y del medio ambiente".

La inserción del artículo 17 en la DUBDH, que trata de cuestiones ambientales y sociales, fue una conquista de los países latinoamericanos en la Unesco, pues los países centrales querían reducir la declaración a cuestiones relacionadas con autonomía aplicada a tecnologías en salud. A partir de entonces, se forma una bioética ambiental latinoamericana (Junges, 2006), que reconoce que el medio ambiente causa exclusión social -o por lo menos, su agravamiento—. La bioética alcanza el campo ambiental, pasando necesariamente por el campo de la bioética social (Garrafa, 2005).

El artículo 17 también es observado en cuanto al respeto del conocimiento tradicional, con sus saberes, cultura y valores. En esta perspectiva, la Pachamama (derechos de la naturaleza) y la filosofía del buen vivir también revelan interculturalidad y desco- 
lonialidad, una vez que la visión de mundo estadounidense-eurocéntrica deja de ser hegemónica (Pombo et al., 2015).

O meio ambiente só é preservado quando se tem uma visão complexa que compreende o ambiente como um sistema integral de interdependências (biosfera) e, para que este sistema esteja em equilíbrio homeostático é necessário que haja biodiversidade possibilitadora das inter-relações. (Junges, 2006, p. 32)

Por el material examinado, se verifica que la bioética global de Potter presenta relación directa con varias proposiciones de la DUBDH, de la Pachamama del buen vivir, a través de un mismo propósito: la preservación del planeta frente a las innovaciones biotecnológicas. La visión biocéntrica amplía el campo de actuación de la bioética global, que apunta la interferencia del medio ambiente en la salud del ser humano y del planeta, algo que la bioética hegemónica principialista no es capaz de visualizar (Garrafa et al., 2016; Maluf, 2011).

\section{Una breve discusión}

El ser humano integra el medio ambiente y, para subsistir, necesita tener consciencia de su poder y de su responsabilidad frente a la naturaleza como un todo. Él precisa adquirir una visión ecosistémica de la naturaleza que lo circunda, saber que es apenas uno de los integrantes de la biósfera, aceptar visiones dispares de mundo, reconocer culturas tra-

5 "El medio ambiente sólo es preservado cuando se tiene una visión compleja que comprende el ambiente como un sistema integral de interdependencias (biosfera) y, para que este sistema esté en equilibrio homeostático, es necesario que haya biodiversidad que posibilite las -inter-relaciones" (Junges, 2006, p. 32, traducción de los autores). dicionales y tutelar la naturaleza. En este intento, la bioética global se vuelve una herramienta indispensable.

El medio ambiente, como recurso natural, independe de fronteras; un ejemplo de esto es la polución ambiental (Moraes, 2002). Involucrar las fronteras ocasiona conflictos de soberanía y vuelve ineficiente la tutela constitucional para el medio ambiente, haciéndose necesaria una interferencia y respectiva tutela internacional (Moraes, 2002). En este contexto, se puede mencionar como referencial teórico e instrumento de protección al medio ambiente la DUBDH, en sus artículos 3, 14 y 17.

Podemos sugerir también, que elpPrincipio de la dignidad previsto en el artículo 3 no se restrinja apenas a la persona humana, sino que su dimensión sea ampliada a otros seres vivos y a la naturaleza en general. Hay autores que defienden que el medio ambiente debería ser considerado patrimonio común de la humanidad, con el propósito de garantizar su integral protección, en consonancia con el desarrollo sostenible (Moraes, 2002).

La aplicación del pensamiento biocéntrico y ecocéntrico en las Constituciones de Ecuador y Bolivia las convirtió en un importante marco legal, para ser acompañado y discutido en ámbitos jurídicos y bioéticos. Esas constituciones vedan de forma expresa la producción, comercialización e importación de material genéticamente modificado, no solo por considerarlo perjudicial para la salud humana, sino también por cuestiones de seguridad alimentaria, para proteger la biodiversidad local.

En nuestras lecturas, encontramos registro de eventos positivos y negativos involucrando la aplicación de la filosofía Pachama- 
ma. La efectividad de la filosofía fue comprobada en el primer veredicto en el mundo donde se reconoció el derecho de un río, el caso Vilcabamba en Ecuador. El río Vilcabamba abastece varias propiedades a su margen y tuvo su ecosistema perjudicado por detritos dejados por la obra de construcción de una carretera, que produjeron erosión de las márgenes y aumento de la incidencia de inundaciones, con destrucción de la fauna y de la flora acuáticas (Gussoli, 2014).

En 2011, la Corte Provincial de Justicia de Loja reconoció al río Vilcabamba como detentor de valor propio, sujeto de derecho, y afirmó que era compromiso de los jueces hacer efectivos los derechos de la naturaleza para que la Constitución fuera cumplida (Gussoli, 2014).

Por otro lado, fueron registrados problemas en la implementación de la Pachamama en Bolivia. No obstante la protección legal direccionada a la naturaleza y a la búsqueda por seguridad alimentaria expresas en la Constitución, que prohíbe la producción y la importación de alimentos genéticamente modificados, hay denuncias de que productos transgénicos ingresan al país a través de importación y de contrabando. El país no exige análisis de los granos que importa, y así los granos modificados no encuentran barreras de acceso. La sociedad se encuentra dividida. Hay grupos que, por cuestiones económicas, reivindican el derecho de cada país para investigar y producir, él mismo, semillas transgénicas, y hay otros que optan por conservar la biodiversidad local (Hannover, 2016; Expansión, 2016).

Muchas personas no logran visualizar el mundo más allá de la modernidad; no reconocen otras maneras de vivir diferentes a la eurocéntrica. La cultura eurocéntrica fue impuesta en América sin considerar la identidad de los pueblos amerindios; no hubo la posibilidad de elección o intercambio de valores buscando un buen vivir social y ambiental.

Hay una deuda histórica mundial con los pueblos amerindios, y las medidas para esa reparación histórica van más allá del rescate de identidad, equidad y justicia: es una cuestión de sobrevivencia. El progreso es comprendido en la modernidad como algo que debe ser alcanzado a cualquier costo. En pocos siglos, la modernidad logró devastar los recursos naturales de forma virulenta, al punto de colocar en riesgo la coexistencia de varios seres vivos y, por consiguiente, la propia existencia humana en la Tierra.

La biodiversidad está transformándose en homogeneidad; el colectivo, en individualismo y egoísmo; la libertad está siendo vinculada a la cantidad de dinero que se posee; la ciencia y la tecnología están siendo direccionadas a los beneficios humanos "rentables financieramente". Estos eventos agravan la crisis ambiental discutida por la bioética global.

Deseosos de evitar un destino incierto para el futuro de la biodiversidad, fuimos a buscar alternativas en la filosofía del buen vivir (Pachamama) y en el Nuevo Constitucionalismo Latinoamericano, no para contener el progreso humano, sino para comprenderlo desde la perspectiva de la bioética global.

La implantación de la filosofía andina en otros países encuentra muchas dificultades debido a conflictos que involucran mundos diferentes e intereses individuales, corporativos y financieros ocultos. A pesar de eso, vienen naciendo pequeños focos de cambio, fomentados por la necesidad urgente de revisión de mentalidades, para minimizar la crisis 
ambiental. Lentamente, el mundo ha direccionado su mirada a otras perspectivas filosóficas, como las doctrinas éticas del ecocentrismo y biocentrismo (Amado, 2014).

\section{Consideraciones finales}

Es bastante difícil alterar visiones de mundo $\mathrm{y}$ antiguos paradigmas, pero no imposible. El concepto de naturaleza como titular de derechos obliga a cambios significativos en la relación hombre y naturaleza, pues esta deja de ser considerada un bien y objeto de relación jurídica, o sea, un simple depósito de mercadurías al servicio del consumismo humano y de sus intereses económicos, para volverse sujeto de derechos. La elevación de la naturaleza a sujeto de derecho es una herramienta para que haya mayor respeto al medio ambiente, a los otros animales y a los propios seres humanos.

Además, el reconocimiento jurídico de la naturaleza como sujeto de derechos se refleja en el ámbito ético, y esto deja una visión de mundo reconocidamente antropocéntrica, para adoptar formalmente una visión de mundo direccionada a la ética de la vida y al ecocentrismo.

De esta forma, el principialismo confirma su insuficiencia como teoría universal para los diferentes contextos y realidades en los más distintos países y regiones. Tales críticas proporcionaron la inclusión en la pauta bioética de temas antes poco explorados como, por ejemplo, los derechos humanos.

Al asociar bioética como campo normativo particular en la atención y cuidado de la vida y de la salud, con derechos humanos como campo normativo universal básico de obligaciones morales y jurídicas para todas las formas de vida, se identifican los valores fundamentales de una ética univer- sal sustentada por la dignidad humana, por la igualdad de derechos, por la libertad, por la justicia, por la fraternidad y por la paz, valores claramente observados en las constituciones de Ecuador y de Bolivia en lo que se refiere a la protección (defensa) de la naturaleza como sujeto de derechos.

La bioética global refuerza la propuesta de la visión Pachamama, en la cual el hombre deja de ser visto como el centro del universo y señor absoluto de la naturaleza, y pasa a ser cuestionado por las transformaciones que genera en la biósfera. La tecnología creada por el hombre genera poder, que, a su vez, genera responsabilidad, tanto frente a las generaciones futuras, como a la naturaleza como un todo. Aunque poderoso, el hombre es parte integrante de la naturaleza y no un ser superior a ella. Los recursos naturales son finitos y deben ser compartidos entre todos los seres que habitan este planeta, por una cuestión de sobrevivencia de la propia biósfera.

Los artículos de la declaración sitúan la bioética dentro de la realidad humana social y concreta, y abren nuevas perspectivas para la reflexión y la acción. Aunque la declaración no es vinculante en sí misma, pretende proporcionar, en las decisiones que serán tomadas o prácticas por ser desarrolladas por aquellos a quienes ella está dirigida, una orientación para la elaboración de leyes nacionales y reglamentos profesionales.

Sin un medio ambiente que posibilite la coexistencia de la biodiversidad, todos los artículos de la DUBDH y del constitucionalismo latinoamericano se volverían insignificantes, pues existe un serio riesgo de que, en el futuro, estos documentos queden huérfanos de aquella que se precian proteger: la biodiversidad natural. 
La DUBDH se presenta como un nuevo referencial ético que permite la utilización de referentes que dirijan la acción en una perspectiva crítica, antihegemónica, social y políticamente comprometida. Arduamente construida y duramente conquistada, el contenido de la declaración consolida un avance concreto para un nuevo referencial epistemológico y una nueva agenda temática para la bioética del siglo XXI, una bioética más humana, más palpable y más cercana a los verdaderos conflictos persistentes que asolan a la mayoría de los países periféricos del planeta.

La publicación de la DUBDH ratifica la importancia de la bioética como instrumento capaz de auxiliar en la resolución de conflictos éticos que atentan contra los derechos humanos, aquí incluidos la preservación de la naturaleza y la protección del medio ambiente, como es preconizado (propuesto) por el artículo 17 de la declaración. En este sentido, la Pachamama y el buen vivir, a pesar de tener su origen en América Latina, deben volverse referencias mundiales, pues la efectiva protección del medio ambiente es independiente de fronteras y es un asunto de interés global, como se propuso en el Nuevo Constitucionalismo latinoamericano.

\section{Referencias}

Afonso, H.W. y Magalhães, J.L.Q. (2011). O estado plurinacional da Bolívia e do Equador: matrizes para uma releitura do Direito Internacional Moderno. Revista Brasileira de Direito Constitucional, (17), 263-276. Recuperado de http://www.esdc.com.br/RBDC/ RBDC-17/RBDC-17-263-Artigo_Henrique_Weil_Afonso_e_Jose_Luiz_Quadros_de_Magalhaes_(O_Estado_Plurinacional_da_Bolivia_e_do_Equador).pdf
Almeida, P. (2014). A visão ecocêntrica do meio ambiente no mundo jurídico. Recuperado de http://paulossalmeidaadv.jusbrasil.com.br/ artigos/151203513/a-visao-ecocentrica-do-meio-ambiente-no-mundo-juridico.

Amado, F. (2014). Direito Ambiental Esquematizado (5ta. Ed). Rio de Janeiro: Forense, Brasil-SP, São Paulo: Método.

Bergel, S.D. (2015). Diez años de la Declaración Universal sobre Bioética y Derechos Humanos. Revista Bioética, 23(3), 446-55.

Boff, L. (2012). ¿Vivir mejor o "el buen vivir"? Recuperado de http://servicioskoinonia.org/ agenda/archivo/obra.php?ncodigo=757

Bolívia, Constitución Política del Estado Plurinacional de Bolivia (2009). Constitución Política del Estado Plurinacional de Bolivia. Recuperado de de http://www.harmonywithnatureun.org/content/documents/159Bolivia\%20Consitucion.pdf

Capra, F. (1996). A teia da vida: uma nova compreensão científica dos sistemas vivos. São Paulo: Cultrix.

Diegues, A.C. (1993). Realidades e falácias sobre pescadores artesanais. Série de Documentos e Relatórios de Pesquisa, (7).

Dulley, R.D. (2004). Noção de Natureza, Ambiente, Meio Ambiente, Recursos Ambientais e Recursos Naturais. Agric. Brasil-SP, 51(2), 15-26.

Equador, Constitución del Ecuador (2008). Constitución del Ecuador. Recueprad de http://www.stf.jus.br/repositorio/cms/ portalStfInternacional/newsletterPortaIInternacionalFoco/anexo/ConstituicaodoEquador.pdf 
Expansión (2016). Bolívia vive um tira y afloja sobre el cultivo com semillas transgênicas. Recuperado de http://www.expansion. com/latinoamerica/2016/01/11/5693cc9aca474165448b4639.html

Gaceta oficial de Bolívia (2010). Ley 071. "Ley de derechos de la madre tierra". Recuperado de http://www.harmonywithnatureun.org/content/documents/158Bolivia\%20Ley\%20071.pdf

Garrafa, V. (2005). Da bioética de princípios a uma bioética interventiva. Revista Bioética, 13(1), 125-34. Recuperado de http:// revistabioetica.cfm.org.br/index.php/revista_bioetica/article/view/97/102

Garrafa, V., Martorell ,L.B. y Nascimento, W.F. (2016). Críticas ao principialismo em bioética: perspectivas desde o Norte e desde Sul. Saúde e Sociedade, 25(2), 442-51.

Gudynas, E. (2010). A política ecológica de Pachamama. recuperado de http://www. correiocidadania.com.br/index.php?option=com_content\&view=article\&i$\mathrm{d}=4955$ :submanchete270810\&cati$\mathrm{d}=62$ :eduardo-gudynas\&Itemid=131

Gussoli, F.K.(2014). A natureza como sujeito de direito na Constituição do Equador: considerações a partir do caso Vilacamba. Recuperado de http://www.direito.ufpr.br/portal/ wp-content/uploads/2014/12/Artigo-Felipe-Gussoli-classificado-em-1-lugar-.pdf

Hannover, C. (2016). Transgénicos: Bolívia no lós produce, pero lós consume. Recuperado de http://www.paginasiete.bo/inversion/2016/7/24/transgenicos-bolivia-produce-pero-consume-103852.html

Jonas, H. (2006). O princípio responsabilidade: ensaio de uma ética para a civilização tecnológica. Rio de Janeiro: Contraponto, PUC-Rio.

Junges, J.R. (2014). Bioética e Meio Ambiente num Contexto de América Latina. Revista Redbioética,1(9), 13-19.

Junges, J.R. (2006). A proteção do meio ambiente na Declaração Universal sobre Bioética e Direitos Humanos. Revista Brasileira de Bioética, 2(1), 21-38.

Maluf, F. (2007). Compromisso dos pesquisadores com comitês de Ética em pesquisa nas dissertações e teses envolvendo seres humanos do programa de pós-graduação em ciências da saúde da Universidade de Brasília no período agosto 1996-dezembro 2006 (Tesis de maestría). Universidade de Brasília, Brasil.

Martínez, E. (2010). Pachamama y Sumak Kawsai. Recuperado de http://www.sicsal.net/reflexiones/CentenarioProanhoEMartinez.pdf

Moraes, A.(2002). Constituição do Brasil interpretada e legislação constitucional. São Paulo: Atlas.

Moura, L.D. (2012). O Novo Constitucionalismo Latinoamericano e o Meio ambiente: as possibilidades de proteção face ao Direito Ambiental Internacional. Recuperado de www.publicadireito.com.br/artigos/?cod=fcde14913c766cf3

Nogueira, C.B.C. y Dantas, F.A.C. (2012). O Sumak Kawsay (Buen Vivir) e o novo constitucionalismo latino-americano: uma proposta para concretização dos direitos socioambientais? Universitas e Direito, 1(1), 24-42. Recuperado de http://www2. pucpr.br/reol/index.php/universitas?dd99=pdf\&dd1=7481 
Pombo, V.B., Junges, J.R. y Nascimento, W.F. (2015). Epistemologia ambiental do Ecologismo Popular e suas consequências para uma bioética ambiental Environmental. Revista Redbioética, 1(11), 140-50. Recuperado de http://www.unesco.org. uy/shs/red-bioetica/fileadmin/shs/redbioetica/Revista_11/BeckPomboetal.pdf

Potter, V.R y Potter, L. (1995). Global bioethics: converting sustainable development to global survival. Medicine and Global Survivel, 2(3), 185-91.

Rivas-Muñoz, F., Garrafa, V., Feitosa, S.F. y Nascimento, W.F. (2015). Bioética de intervención, interculturalidad y no-colonialidad. Saúde e Sociedade, 24(supl 1), 141-51.

Singer, P. (2002). Ética Prática. São Paulo. Martin Fontes.

Singer, P. (2010). Libertação Animal. São Paulo: WMF Martins Fontes.

Souza Filho, C.F.M. (1999). Os direitos invisíveis. En F. Oliveira y M. C. Paoli (Orgs.),
Os Sentidos da Democracia: políticas do dissenso e hegemonia global (pp. 307-334). São Paulo: Vozes, FAPESP.

Tolentino, Z.T. y Oliveira, L.P.S. (2015). Pachamama e o direito à vida: uma reflexão na perspectiva do novo constitucionalismo latino-americano. Veredas do Direito, 12(23), 313-35. Recuperado de http:// www.domhelder.edu.br/revista/index. php/veredas/article/download/393/450

Unesco. (2005). Declaração Universal sobre Bioética e Direitos Humanos. Recuperado de http://unesdoc.unesco.org/images/0014/001461/146180por.pdf

Viana, M.G. (2013). A Terra como sujeito de Direitos. Revista da Faculdade de Direito, 34(2), 247-75. Recuperado de http:// www.revistadireito.ufc.br/index.php/ revdir/article/viewFile/106/87

Winckler, S. y Pereira, R. (2013). O Estado de Bem-estar e o Estado de Bem Viver: cidadania e desenvolvimento integral. Recuperado de http://www.publicadireito.com. br/artigos/?cod=ec2f08ae409f4a81 